\title{
Radiation Response of SiGe BiCMOS Mixed-Signal Circuits Intended for Emerging Lunar Applications
}

\author{
Laleh Najafizadeh, Akil K. Sutton, Bongim Jun, John D. Cressler, Tuan Vo, Omeed Momeni, \\ Mohammad Mojarradi, Chandradevi Ulaganathan, Suheng Chen, Benjamin J. Blalock, Yuan Yao, \\ Xuefeng Yu, Foster Dai, Paul W. Marshall and Cheryl J. Marshall
}

\begin{abstract}
The effects of proton irradiation on the performance of key devices and mixed-signal circuits fabricated in a SiGe BiCMOS IC design platform and intended for emerging lunar missions are presented. High-voltage (HV) transistors, SiGe bandgap reference (BGR) circuits, a generalpurpose high input impedance operational amplifier (op amp), and a 12-bit digital-to-analog converter (DAC) are investigated. The circuits were designed and implemented in a first-generation SiGe BiCMOS technology and were irradiated with $63 \mathrm{MeV}$ protons. The degradation due to proton fluence in each device and circuit was found to be minor, suggesting that SiGe HBT BiCMOS technology could be a robust platform for building electronic components intended for operation under extreme environments.
\end{abstract}

Index Terms-About four key words or phrases in alphabetical order, separated by commas.

\section{INTRODUCTION}

E lectronic circuits capable of operating reliably in extreme environment conditions are highly desirable for space applications, since they can greatly improve robotic system architecture and reduce overall system power drain, weight and complexity by eliminating the need for shielded "warm boxes" for electronic systems and their consequent highly centralized architectures. Examples of extreme environment conditions include: operation down to very low temperatures (e.g., down to $43 \mathrm{~K}$ ); up to very high temperature (e.g., up to

L. Najafizadeh, A. K. Sutton, and J. D. Cressler are with the School of Electrical and Computer Engineering, Georgia Institute of Technology, Atlanta, GA 30332 USA (Email: laleh@ece.gatech.edu).

B. Jun was with Georgia Institute of Technology, Atlanta, GA 30332 USA. She is now with Spectrolab, Inc., 12500 Gladstone Ave., Sylmar, CA 91342 USA.

T. Vo and M. Mojarradi are with Jet Propulsion Laboratory, Pasadena, CA 91109 USA.

O. Momeni was with Jet Propulsion Laboratory, Pasadena, CA 91109 USA. $\mathrm{He}$ is now with the School of Electrical and Computer Engineering, Cornell University, Ithaca, NY 14853 USA.

C. Ulaganathan, S. Chen, and B. J. Blalock are with the Department of Electrical and Computer Engineering, University of Tennessee, Knoxville, TN 37996 USA.

Y. Yao, X. Yu, and F. Dai are with the Department of Electrical and Computer Engineering, Auburn University, Auburn, AL 36849 USA.

being irradiated. The samples were irradiated with $63 \mathrm{MeV}$
P. W. Marshall is a consultant to NASA-GSFC, Greenbelt, MD 20771 USA.

C. J. Marshall is with NASA-GSFC, Greenbelt, MD 20771 USA.

$573 \mathrm{~K}$ ); and operation in a radiation-rich environment. The Moon is a prototypical example of an extreme environment. The ambient temperature on the Moon ranges from $+120{ }^{\circ} \mathrm{C}$ (in the sunshine) to $-230{ }^{\circ} \mathrm{C}$ (in the shadowed polar craters), and the surface of the Moon is exposed to cosmic rays and solar flares, as well as total ionizing dose (TID). Among all available technology platforms, SiGe heterojunction bipolar transistor (SiGe HBT) technology has recently emerged as a viable candidate [1] for such envisioned applications. Due to the bandgap-engineered nature of SiGe HBTs, both their dc and ac performance improves with cooling [2]-[3]. SiGe HBTs also have a desirable side benefit of possessing an inherent hardness to ionizing radiation, and have also been shown to be TID tolerant down to $77 \mathrm{~K}$ operating temperatures [4]. In addition to offering high performance transistors, SiGe technology platforms also maintain fabrication compatibility with low-cost Si CMOS foundry processes, making it an excellent choice for building low-cost, highly integrated, mixed-signal circuits and systems. In order to prove the feasibility of SiGe technology for the implementation of electronic circuits required for the planned NASA lunar missions, key mixed-signal circuits must be implemented in this technology and thoroughly characterized under extreme environment conditions.

This paper presents experimental results of the effects of 63 $\mathrm{MeV}$ proton irradiation on a number of key mixed-signal $\mathrm{SiGe}$ BiCMOS circuit blocks, from voltage references to digital-toanalog converters, and for the first time demonstrates that these circuits can indeed operate reliably under lunar extreme environment conditions (i.e., under radiation exposure and across wide temperature ranges).

\section{II.EXPERIMENT}

The major goal of this work was to assess the impact of radiation exposure on the performance of several key mixedsignal SiGe circuits. Each circuit was mounted in 28 or 40 pin ceramic packages, wire bonded, and characterized before protons at $300 \mathrm{~K}$ at the Crocker Nuclear Laboratory at UC 


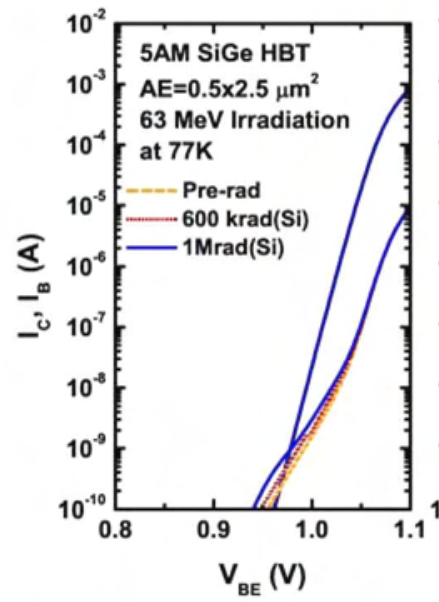

(a)

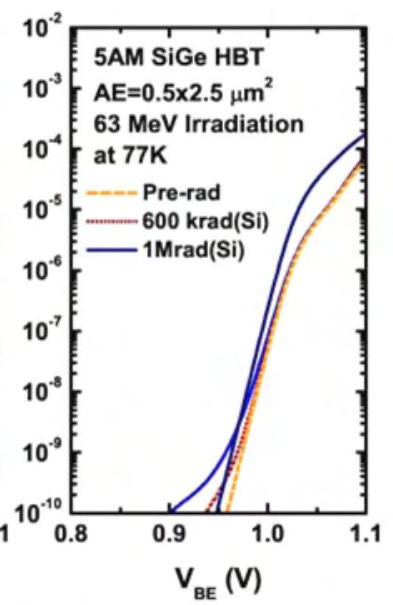

(b)
Fig. 1. (a) Forward-mode and (b) inverse-mode Gummel characteristics for a $5 \mathrm{AM} \mathrm{SiGe} \mathrm{HBT}$, irradiated and measured at $77 \mathrm{~K}$.

Davis. The dosimetry measurements used a five-foil secondary

emission monitor calibrated against a Faraday cup, and Ta scattering foils located several meters upstream of the target establish a beam spatial uniformity of $15 \%$ over a $2.0 \mathrm{~cm}$ radius circular area. The dosimetry system has been previously described [5], and is accurate to about $10 \%$. Estimates of mission-life total dose levels on the lunar surface (behind 100 mil of standard $\mathrm{Al}$ shielding) are in the range of $100 \mathrm{krad}(\mathrm{Si})$, and hence total dose ionization levels in the range of $200-600 \mathrm{krad}(\mathrm{Si})$ were used here to emulate worst case conditions. Irradiated circuits were subsequently measured across temperature.

\section{Process TECHNOLOGY}

The technology chosen for this project is a commercially available, first-generation $\mathrm{SiGe}$ (IBM's $\mathrm{SiGe} 5 \mathrm{AM}$ ) technology. This SiGe technology is a four-level metal process and features SiGe HBTs with an emitter width of 0.5 $\mu \mathrm{m}$ and a unity gain cut-off frequency and maximum frequency of oscillation of $45 \mathrm{GHz}$ and $60 \mathrm{GHz}$ at $300 \mathrm{~K}$, respectively, offering plenty of performance for the intended lunar applications (the required frequency of operation for such applications is typically in the range of $100-200 \mathrm{MHz}$ (maximum)). The technology also offers conventional nMOS and pMOS transistors with a nominal $\mathrm{L}_{\text {eff }}$ of $0.35 \mu \mathrm{m}$, as well as polysilicon and diffused resistors, and various capacitors. The response of first-generation SiGe HBTs to proton irradiation at both $300 \mathrm{~K}$ and $77 \mathrm{~K}$ has been previously reported [4], [6]. Fig. 1 shows the forward-mode and inversemode Gummel characteristics of a $0.5 \times 2.5 \mu \mathrm{m}^{2} 5 \mathrm{AM}$ SiGe HBT, irradiated and measured at $77 \mathrm{~K}$. The measured equivalent total gamma doses were $600 \mathrm{krad}(\mathrm{Si})$ (a proton influence of $4.3 \times 10^{12} \mathrm{p} / \mathrm{cm}^{2}$ ) and $1.0 \mathrm{Mrad}(\mathrm{Si}$ ) (a proton fluence of $7.2 \times 10^{13} \mathrm{p} / \mathrm{cm}^{2}$ ). All pins were grounded during irradiation. As expected, with the increase in the total dose, the forward-mode base current leakage increases at low injection. This is due to the increase in the recombination

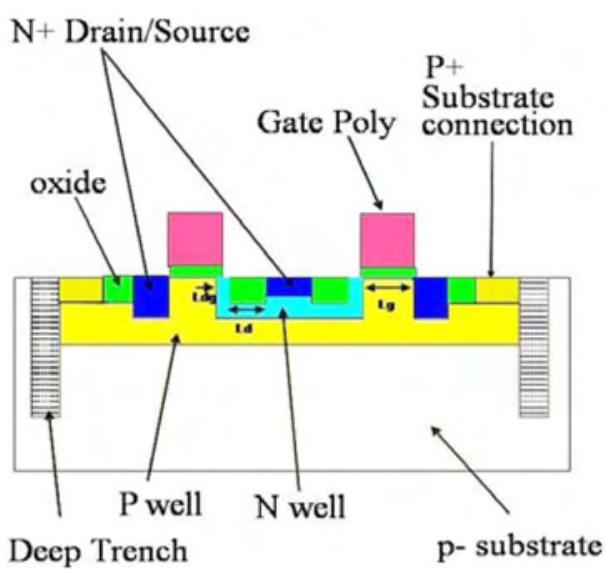

Fig. 2. Cross-section of the high voltage (HV) transistor.

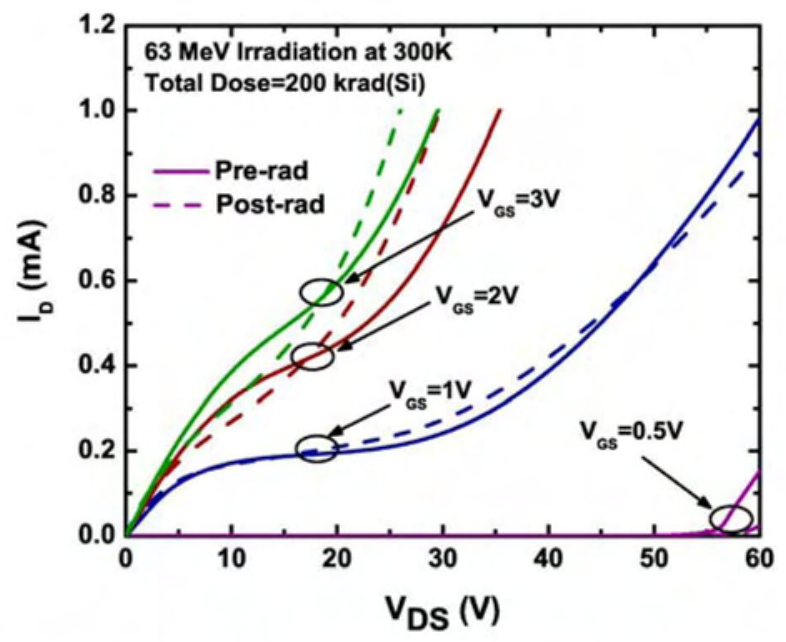

Fig. 3. I-V characteristics of a $\mathrm{HV}$ nMOS transistor before and after irradiation.

current in the EB space-charge region as the radiation-induced generation-recombination traps near the EB spaced oxide increase with total dose [7]. The degradation in the base current of the inverse-mode characteristics verifies the existence of the radiation-induced traps in the $\mathrm{CB}$ junction. The collector current remains unchanged after irradiation.

\section{MIXED-SIGNAL BUILDING BLOCKS}

In this section we present the design, implementation, and radiation response of a number of key SiGe mixed-signal building block circuits intended for lunar applications. Detailed circuit analysis and the circuit techniques developed for robust operation over extreme temperatures are included in the full paper.

\section{A. High Voltage Transistors}

To demonstrate a high-voltage (HV) capability for motor actuation and control systems in a first-generation $3.3 \mathrm{~V} \mathrm{SiGe}$ BiCMOS technology, HV transistors were implemented using special layout techniques. A cross-section of the HV transistor is shown in Fig. 2. This device is based upon a conventional $\mathrm{n}$-channel MOSFET, but the drain area is surrounded by an $\mathrm{n}$ - 


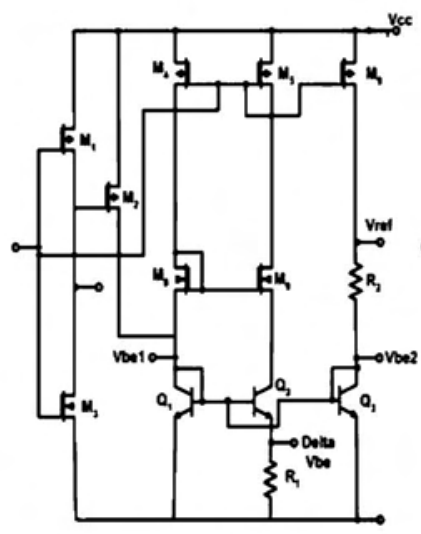

(a)

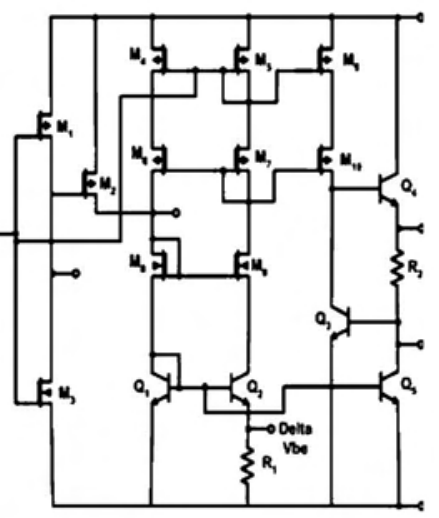

(b)
Fig. 4. Schematic of (a) uncompensated (b) compensated BGR circuits.

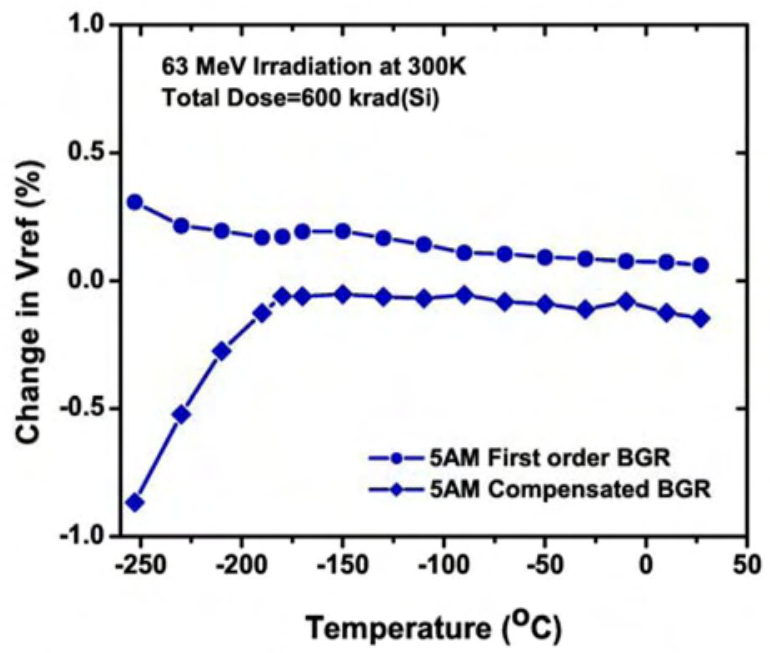

Fig. 5. Percentage change in the output voltage of 5AM BGRs after 600 $\operatorname{krad}(\mathrm{Si})$ irradiation.

well and is used to define an additional "drift" region. Increase in the drain-to-source voltage will result in an increase to this drift channel, improving the breakdown voltage. A HV transistor with $\mathrm{W}=40.45 \mu \mathrm{m}$ and $\mathrm{L}=2 \mu \mathrm{m}$ was irradiated with all pins grounded. The measured equivalent total gamma dose was $200 \mathrm{krad}(\mathrm{Si})$. The output characteristics of the $\mathrm{HV}$ transistor before and after irradiation are shown in Fig. 3. A blocking voltage of $57 \mathrm{~V}$ was achieved. For $\mathrm{V}_{\mathrm{GS}}$ of 1 $\mathrm{V}$, the output curve shows negligible change after irradiation. As the gate-source voltage increases, differences are observed between pre-rad and post-rad output curves. More data is required to investigate the reasons.

\section{B. SiGe Voltage References}

Precise voltage references are a key building block for virtually all electronic circuits and systems, including analogto digital and digital-to-analog converters. The proton response of SiGe bandgap voltage references (BGR) has been previously investigated [8]. Fig. 4 shows schematics of two BGR circuits designed and implemented in IBM SiGe 5AM technology. Fig. 4-a shows the uncompensated BGR circuit. The output voltage of this circuit is simply defined by the summation of the base emitter voltage of transistor $\mathrm{Q}_{3}$ and the proportional to the absolute temperature (PTAT) voltage across resistor $R_{2}$. Fig. 4-b shows the schematic of a BGR in which the temperature dependence of the current gain is used for output curvature compensation [9]. In both circuits, several pads have been inserted to monitor the voltages at internal nodes. Both circuits were irradiated while under operational bias. The measured equivalent total gamma dose was 600 $\operatorname{krad}(\mathrm{Si})$. Fig. 5 shows the percent change in the output voltage of both circuits after irradiation, as a function of temperature. As can be seen, the change in the output voltage of both BGRs is less than $1 \%$, even at cryogenic temperatures. To identify the radiation sensitive parts of the circuit, the voltages of the internal nodes were also measured before and after irradiation. Deviation from linearity of the base-emitter voltage before and after irradiation for the two internal transistors $Q_{1}$ and $Q_{3}$ was measured and it was found out that the proton irradiation has minimal effect on the temperature dependence of the base emitter voltage. The percentage change in the base-emitter voltage difference of transistors $\left(Q_{1}\right.$ and $\mathrm{Q}_{2}$ ) in both BGR circuits was also measured. This voltage is the basis for the PTAT voltage generated inside the BGRs. The measured percentage change in this voltage for both circuits was larger than the change in the base-emitter temperature dependency, and as a result the minor changes in the output voltage of both BGRs can be attributed to the change in the PTAT voltage, consistent with results in [8]. As mentioned above, the overall change in the performance of the BGR after irradiation is negligible even down to cryogenic temperatures.

\section{General-Purpose High-Z Input Operational Amplifier}

General-purpose operational amplifiers (op amps) are fundamental building blocks for many mixed-signal integrated circuits. The schematic of the general-purpose op amp implemented in SiGe 5AM technology is shown in Fig. 6 [10]. The circuit is a two-stage op-amp, which provides high gain by utilizing a p-type differential input stage and a singleended class-AB output stage. Ground-sensing capability is facilitated by using p-type input devices and a biasing scheme based on the common-mode feedback loop within the input stage, implemented by transistors $\mathrm{Mp}_{4}-\mathrm{Mp}_{8}$ and $\mathrm{Mn}_{3}-\mathrm{Mn}_{4}$. The internal frequency compensation uses pole-zero cancellation with two Miller capacitors and their corresponding zero nulling MOS (active) resistors. The circuit provides a gain bandwidth product of about $2 \mathrm{MHz}$. The circuit was irradiated with all pins grounded to a measured equivalent total gamma doses of 30,100 and $300 \mathrm{krad}(\mathrm{Si})$. The open loop gain of the general-purpose op amp before and after irradiation was measured and is plotted in Fig. 7. As can be seen, the change in the open-loop gain due to proton irradiation is minimal. Table I summarizes the measurement results before and after irradiation and shows that the circuit performance has changed negligibly after proton irradiation.

\section{12-bit Digital-to-Analog Converter}

Digital-to-analog converters (DAC) are essential building blocks for modern mixed-signal systems. The block diagram 
TABLE I

PERFORMANCE METRICS OF OP AMP BEFORE AND AFTER PROTON IRRADIATION AT ROOM TEMPERATURE.

\begin{tabular}{|c|c|c|c|c|c|c|c|c|c|c|c|}
\hline $\begin{array}{l}\text { OpAmp } \\
\text { Circuit }\end{array}$ & $\begin{array}{c}\text { BW } \\
(\mathrm{MHz})\end{array}$ & $\begin{array}{l}\mathrm{AOL} \\
(\mathrm{dB})\end{array}$ & $\begin{array}{c}\text { PM } \\
\left(\mathrm{C}_{\mathrm{L}}=50 \mathrm{pF}\right)\end{array}$ & $\begin{array}{l}\text { Offset } \\
(\mathrm{mV})\end{array}$ & $\begin{array}{c}\text { SR } \\
\text { (V/us) } \\
\end{array}$ & $\begin{array}{l}\mathrm{t}_{\text {rise }} \\
\text { (ns) }\end{array}$ & $\begin{array}{l}\mathrm{t}_{\mathrm{fall}} \\
(\mathrm{ns})\end{array}$ & $\begin{array}{c}\text { NoISE@100KHz } \\
(\mathrm{V} / \mathrm{Hz})\end{array}$ & $\begin{array}{c}\text { PSRR } \\
(\mathrm{dB})\end{array}$ & $\begin{array}{c}\text { CMRR } \\
(\mathrm{dB})\end{array}$ & $\begin{array}{c}\text { ICMR } \\
(\mathrm{V})\end{array}$ \\
\hline Pre-rad & 3.50 & 85.80 & 60.00 & 1.41 & $6.60,-8.10$ & 97.00 & 93.00 & 30.60 & 59.70 & 52.00 & $0-2.76$ \\
\hline TID $=300 \mathrm{krad}(\mathrm{Si})$ & 3.64 & 84.40 & 58.00 & 1.43 & $7.50,-5.80$ & 91.00 & 91.00 & 45.10 & 62.50 & 59.30 & $0-2.84$ \\
\hline
\end{tabular}

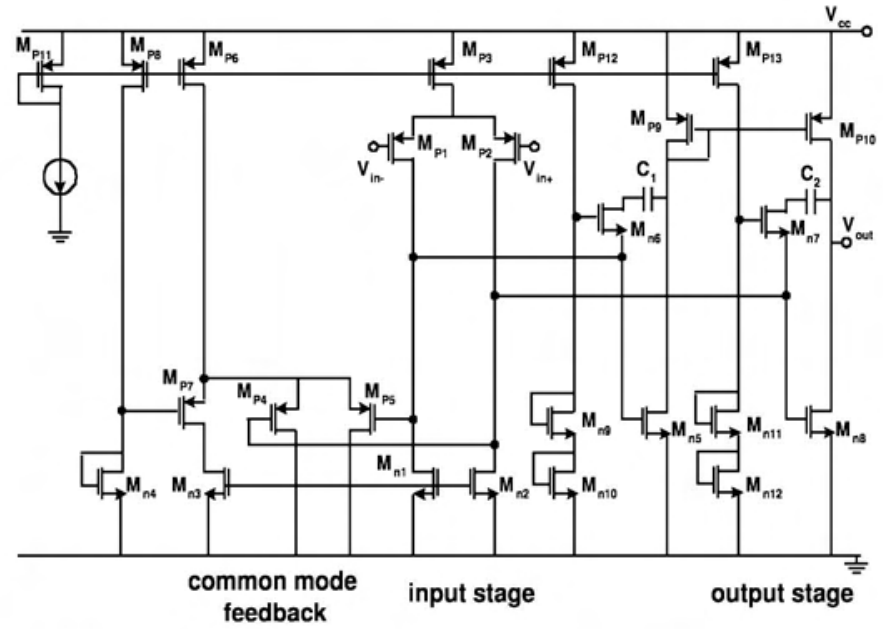

Fig. 6. Schematic of general purpose high-Z input op amp.

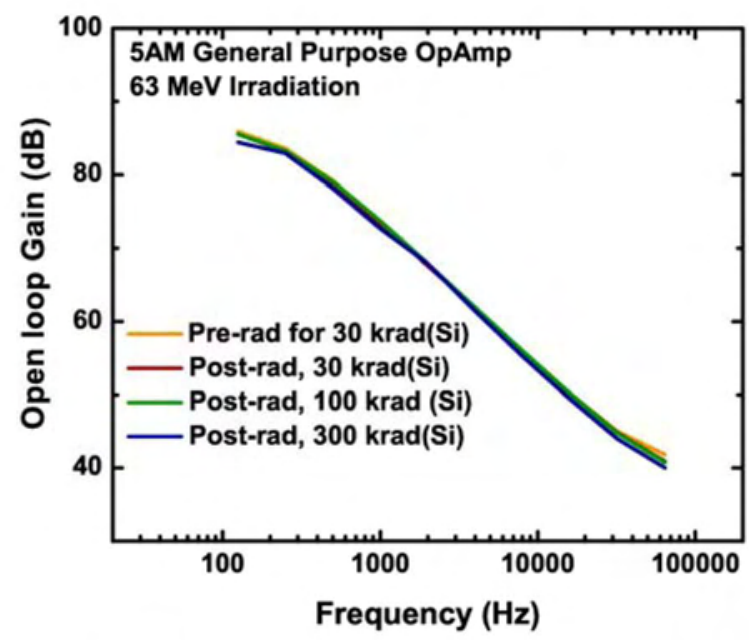

Fig. 7. Open loop gain as a function of frequency for pre-irradiation and after proton exposure.

of the 12 bit DAC implemented in SiGe 5AM technology is shown in Fig. 8. The DAC was designed based upon a 6 $\mathrm{MSB}+4 \mathrm{NSB}+2 \mathrm{LSB}$ segmented current steering architecture, and includes thermometer decoder, current switch logic array, segmented current source array, clock driver, BGR and biasing circuits. Special circuit design techniques were also employed

for ultra-wide temperature range operation. The circuit was irradiated with all pins grounded to total dose level of 300 $\operatorname{krad}(\mathrm{Si})$. Fig. 9 shows the measured $121 \mathrm{kHz}$ output waveforms of the DAC operating at $-180^{\circ} \mathrm{C}$ before and after irradiation. Measurement results indicate that the DAC shows robust radiation tolerance even down at cryogenic

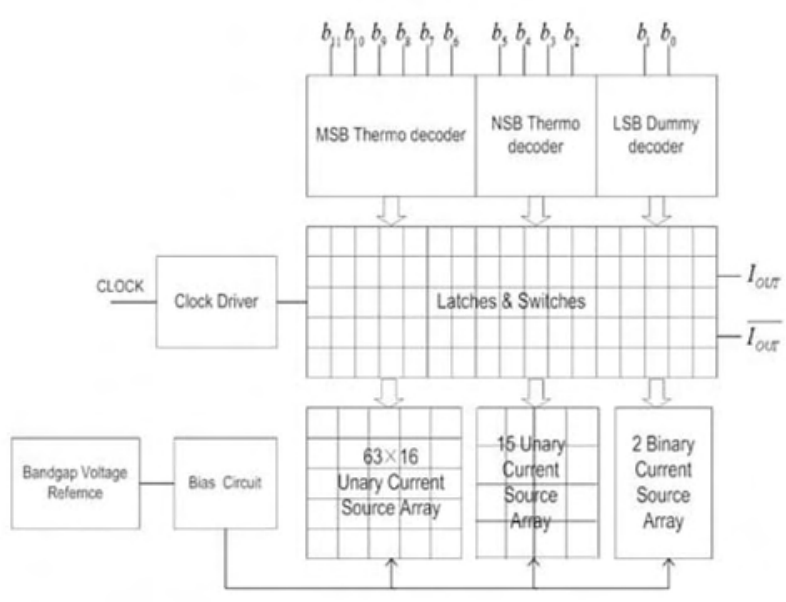

Fig. 8. Block diagram of segmented current steering DAC.

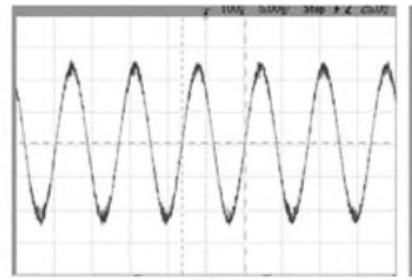

(a)

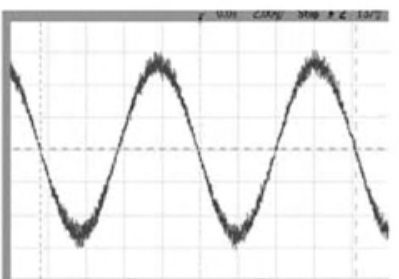

(b)
Fig. 9. Measured differential output voltage of DAC at $-180 \cdot \mathrm{C}$, a) before irradiation $b$ ) after irradiation.

temperatures.

\section{V.SUMMARY}

We have presented the experimental results on the effects of $63 \mathrm{MeV}$ proton irradiation on key mixed-signal devices and circuits implemented in a SiGe BiCMOS technology platform. High-voltage (HV) transistors, SiGe bandgap reference (BGR) circuits, a general purpose high input impedance operational amplifier (op amp), and a 12-bit digital-to-analog converter (DAC) were designed in first-generation SiGe technology and were irradiated with $63 \mathrm{MeV}$ protons at the dose rate of 1 $\operatorname{krad}(\mathrm{Si}) / \mathrm{s}$. The degradation associated with proton fluence in each device and circuit was found to be minor, even at cryogenic temperatures, suggesting that SiGe HBT BiCMOS technology is an ideal candidate for building electronic components intended for lunar missions 


\section{ACKNOWLEDGMENT}

The authors would like to thank M. Watson, D. Frazier, A. Keys, D. Hope, K. LaBel, L. Cohn, A. Joseph, the NASA SiGe ETDP team for their contributions and support of this work. This work was supported by the NASA SiGe ETDP program, the Defense Threat Reduction Agency under the Radiation Hardened Microelectronics Program, NASA-GSFC under the NASA Electronic Parts and Packaging (NEPP) program, an AFOSR MURI program, and the Georgia Electronic Design Center at Georgia Tech.

\section{REFERENCES}

[1] J. D. Cressler and G. Niu, Silicon-Germanium Heterojunction BipolarTransistors, 1st ed. Boston, MA: Artech House, 2003.

[2] B. Banerjee, S. Venkataraman, Y. Lu, Q. Liang, C. Lee, S. Nuttinck, D. Heo, Y. J. Chen, J. D. Cressler, J. Laskar, G. Freeman, and D. C. Ahlgren, "Cryogenic operation of third-generation, 200-GHz peak-fT, silicon-germanium heterojunction bipolar transistors," IEEE Trans. Elec.Dev., vol. 52, pp. 585-593, Apr. 2005.

[3] R. Krithivasan, Y. Lu, J. D. Cressler, J.-S. Rieh, M. H. Khater D. Ahlgren, and G. Freeman, "Half-tetahertz operation of SiGe HBTs," IEEE Elec. Dev. Lett., vol. 27, pp. 567-569, Jul. 2006.

[4] A. P. G. Prakash, A. Sutton, R. Diestelhorst, G. Espinel, J. Andrews, B. Jun, J. D. Cressler, and C. J. Marshall, "The effect of irradiation temperature on the proton response of SiGe HBTs," IEEE Trans. Nucl. Sci., vol. 53, pp. 3175-3181, Dec. 2006.

[5] P. W. Marshall, C. J. Dale, M. A. Carts, and K. A. LaBel, "Particleinduced bit errors in high performance fiber optic data links for satellite data management," IEEE Trans. Nucl. Sci., vol. 41, pp. 19581965, Dec. 1994.

[6] J. M. Roldan, G. Niu, W. E. Ansley, J. D. Cressler, S. D. Clark, and D. C. Ahlgren, "An investigation of the spatial location of proton-induced traps in SiGe HBTs," IEEE Trans. Nucl. Sci., vol. 45, pp. 2424-2429, Dec. 1998.

[7] J. D. Cressler, R. Krithivasan, G. Zhang, G. Niu, P. W. Marshall, H. s. Kim, R. A. Reed, M. J. Palmer, and A. J. Joseph, "An investigation of the origins of the variable proton tolerance in multiple SiGe HBT BiCMOS technology generations," IEEE Trans. Nucl. Sci., vol. 49, pp. 3203-3207, Dec. 2002.

[8] L. Najafizadeh, M. Bellini, A. P. G. Prakash, G. A. Espinel, J. D. Cressler, P. W. Marshall, and C. J. Marshall, "Proton tolerance of SiGe Precision Voltage References for Extreme Temperature Range Electronics," IEEE Trans. Nucl. Sci., vol. 53, pp. 3210-3216, Dec. 2006.

[9] I. Lee, G. Kim, and W. Kim, "Exponential curvature-compensated BiCMOS bandgap references," IEEE J. of Solid-State Circuits, vol. 29, pp. 1396-1403, Nov. 1994.

[10] C. Ulaganathan, Design and Analysis of a General Purpose Operational Amplifier for Extreme Temperature Operation. University of Tennessee: M.S. Thesis, May 2007. 